\title{
Internal and External Audit in the Function of the Management of the Trade Companies
}

\author{
Ermelinda Satka \\ Agriculture University of Tirana, Tirana, Albania
}

\begin{abstract}
In the author's country, trade companies are facing with a number of challenges and different difficulties related directly to the exercise of internal and external audit of the companies. One of many factors that contribute to the management and implementation of audit relates with the staff, professionals, and implements of company policies. For this reason, the purpose of the study is to identify and describe how the internal and external audit is accomplished and functions in private sector (commercial companies). The qualitative method is used to realize this study. The main instrument used for data collection was semi-structured interviews with 15 employees in trade company. Data analysis showed that the internal audit exercised rather than external audit inside the company. According to professionals, the audit often brings conflicts in the company due to the absence of a clear definition of audit instructions and lack of training on the importance or effectiveness of the audit. One of the most important results of this study emphasizes that professional audit staff is important and must be given greater attention by the leaders. For this reason, it is recommended in the future to draft specific guidelines on auditing and implementation to be more frequent in order to achieve the effectiveness of management of the company. Also, it is recommended that more studies should be conducted on this topic for the future.
\end{abstract}

Keywords: trade companies, internal audit, external audit, management, control

Private sector companies are complexes and are facing with challenges that do not enable the provision of essential services to the public. The complexity and their size complicate the administration with full efficiencies of technical and financial resources. In order to ensure that the company is working effectively, it is imperative that the audit service functions according to the law.

At present, all large corporations have the department of internal and external audit. The Institute of Internal Auditors established in 1941 is a global organization with more than 80,000 members and branches in all world cities. The institute defines internal auditing as an independent activity that gives objective assurance and designed consultations with the aim to adding value and improving the companies operations, helping the company achieve its objectives by bringing a disciplinary and systematic approach in the evaluation of the risk management, control, and leadership processes.

The essential features of an effective internal audit department are as follows:

(1) Independence, professional skills, and staff training;

(2) Relations;

Corresponding author: Ermelinda Satka, Msc, Faculty of Economics and Agribusiness, Agriculture University of Tirana, Tirana, Albania; research field: current development in economy. 
(3) Planning, control, evidences, and verifications;

(4) Assessment, reporting and monitoring.

Internal audit will help management in the risk assessment and corporate governance, as one of its objectives is to assist in maximizing the benefits. It is management's responsibility to maintain internal control system and ensure that resources are directed properly.

On the other hand, global experiences emphasize that external audit is the audit form committed by a third party for the purpose, among others, mainly verifying that the financial statements are presented in the correct way. The uniqueness of this audit is related to the impartiality of the process and it serves to provide assurance that the funds are spent in accordance with the law, regulatory acts, and policies of the company. The most common external audit is to audit the financial statements, which will judge the reliability of financial reporting of a society in accordance with accepted accounting principles. The external audit is often seen as an annual obligation.

In the case of the author's country, the role of methodological guidance for all audit pyramid and external audit of the public sector (government), is played by the State Audit Institution (KLSH), a constitutional institution established on the basis of the transformation of the facility, from the period of the centralized economy. But not least, external audit is being conducted by the private sector, Institute of Authorized Experts (IEKA) specifically, created in 1997 and it performs audits in accordance with International Standards on Auditing (SNA).

\section{Purpose of the Study}

To identify and describe how the internal and external audit is accomplished and functions in the private sector (commercial companies).

\section{Hypothesis}

Internal and external audit helps in the management of commercial companies and provides an effective function and effective application of financial and human resources.

\section{External Audit Reports and External Audit for Users and Management}

The external audit is the audit form committed by a third party for the purpose, among others, mainly verifying that the financial statements are presented in the correct way. However, an external audit is not limited, and often is being asked by companies for specific issues or activities, for specific periods of time.

External audit mainly the legal, is regulated by special acts since 1985, amended in 1989, and in 2006 adopted the International Standards on Auditing (SNA). Since 1985, it was decided as the essential task of auditing the financial statements for auditors, in accordance with SNA, and in accordance with the requirements of professional ethics, to express an opinion on them if they show a right and real view at the end of the year. Audit reports are the final product of this mission.

There are two types of audit report: unqualified reports and qualified reports.

\section{Unqualified Reports}

This is the most common report issued with financial statements. It is known as a clean report. SNA emphasizes that "an unqualified opinion on the financial statements is expressed when the auditor's judgment 
gives a fair and true financial situation of the company and is prepared in accordance with relevant accounting or other requirements". The trial ends when:

(1) The financial statements have been prepared using appropriate accounting policies that are applied consistently;

(2) The financial statements are prepared in accordance with relevant legislation, policies, or applicable accounting standards (and any departures are adequately explained in the financial statements).

\section{Qualified Audit Reports}

There are three types of qualified report, which become appropriate depending on circumstances. These reports will contain:

(1) An "exception" of the opinion;

(2) A "negative" opinion;

(3) A "disclaimer of opinion".

\section{Internal Audit}

The Institute of Internal Auditors has determined the internal audit as an insurance activity and independent consulting, designed to add value and improve an organization's objectives. It also helps the company in achieving its objectives, and this improves the effectiveness of risk management, control, and governance. Internal audit is defined by the Internal Audit Guidelines in 1990 as an independent evaluation function that is established by the management of a company to review the internal control system as a service. It objectively examines, evaluates, and reports on the adequacy of internal control as a proper use, economic and effective use of resources. The essential features of an effective internal audit department are as follows:

(1) Independence, professional skills, and staff training;

(2) Relationships;

(3) Planning, control, records, verifications;

(4) Assessment, reporting, and monitoring.

This is a management responsibility to determine the degree of the internal control and not to depend on internal audit as a substitute for these checks. It is the responsibility of management to maintain internal control system and ensure that resources are directed properly. This, of course, will include a responsibility for preventing and detecting fraud. If an internal auditor discovers fraud or any negligence, they should report their suspicions to the appropriate management level.

\section{Independence}

This is achieved through organizational status of internal auditing. It is clear that it must have the freedom to function effectively. Management support is essential and internal audit should determine its own policies, in consultation with management. The head of internal audit should have direct access to the freedom to report to all executives and employees of the company. The main attribute of independence is the ability to report the highest level of company management. Every internal auditor should have an objective attitude and be able to exercise independent judgment, express opinions, and make recommendations, without any pressure scale.

\section{Personnel and Training}

Guidelines for Auditing Practices Board (APB) declare that: 
(1) Effectiveness of internal audit depends largely on the quality, training, and experience of its staff. The goal should be the appointment of appropriate personnel, taking into consideration the personal qualities and potential. After that, you must take steps to ensure the necessary experience, training, and continuous professional training;

(2) Internal Audit Unit should be managed by the internal audit staff that should be qualified and should have extensive experience in internal audit and management. They must plan and control direct motivation of available resources, ensuring that the objectives and responsibilities of internal audit are accomplished;

(3) The full range of the duties may require personnel audit to attract a variety of disciplines. Internal audit effectiveness can be increased by using specialized staff, especially technical nature of internal audit activities;

(4) Internal Audit Unit should employ personnel with different levels of skills, qualifications, and experience, in order to meet the requirements of each task of internal audit.

Auditors need to be trained in accordance with the changes of procedure and legislation. All audit staff should undertake continuous professional development. This should be checked on a yearly basis and by the staff evaluation process.

\section{Relationships}

Auditors have relationships with a wide range of employees and managers and it is important for them to have confidence in the audit process. The managers feel a real need for internal audit, to help them to verify that the system is working in line with their expectations. It is known that some managers, directors, or employees of the company discuss the need for the audit. The interpersonal skills of audit are very important in this case. The interview is an essential ingredient in the planning process. When the audit is complete, the auditors will want to discuss the findings and recommendations of the management before the report is issued. This is an essential and important feature of a good working relationship between the auditors (audit) and management.

\section{Planning, Control, and Registration}

The head of internal audit will want a strategic audit plan, which will address the company's audit approach over a period of 2-5 years. The internal audit guidelines declare the main goals of the internal audit planning as follows:

(1) To define the priorities and the creation of cost-effective to achieve the objectives of the audit;

(2) To assist in the direction and control of audit work;

(3) To assist in providing the attention in critical aspects of the audit work;

(4) To assist in providing that the work is performed in accordance with predetermined objectives.

According to the instructions, the stages of audit planning are as follows:

(1) To identify the organization's objectives;

(2) To define the objectives of the internal audit;

(3) To consider relevant changes in legislation and other external factors;

(4) To get a thorough understanding of the organization's systems, structure, and operations;

(5) To identify, appreciate the risks degree to which the organization is exposed;

(6) To consider changes in structure of the organization;

(7) To consider the strong knowledge and weaknesses in the internal control system;

(8) To consider the management concerns; 
(9) To determine the type of audit, e.g. systems, verification, or value for money;

(10) To estimate the necessary staff resources.

The audit plan is become like a list of assignments weekly or monthly undertaken by the staff.

\section{Assessment of Internal Control Systems}

It is advised and recommended a based approach system on internal audit, which means that the internal auditor is a control expert. APB guidance for internal auditors clearly emphasizes that the controls should ensure that the processes meet the objectives of the systems. The main objectives of the system of internal control, according to the instructions are as follows:

(1) To ensure the compliance of management policies and directives in order to achieve the organization's objectives;

(2) To protect the assets;

(3) To ensure the relevance, reliability, and integrity of information;

(4) To ensure compliance with the statutory requirements.

During the assessment of internal control systems, internal auditor should consider the effect that all the controls have on each other as well as related systems. As part of the planning process, the internal auditor should identify the full range of systems within the organization. For the systems that will be examined, the internal auditor should establish appropriate criteria to determine whether controls are adequate and help achieve the objectives of the system.

\section{Audit Engagement in Consulting, Audit Cards, and Management Letters}

An advisory engagement is a review of systems in order to improve the existing controls. Compared with systems based audits, advisory engagement is limited because it does not test the existing controls internally, but simply notes the design/construction of the system under consideration. Besides counseling, internal auditors perform consulting and service. Internal auditors when performing consulting services operate in an advisory capacity for the management of an organization.

This means that the internal auditors have an active advisory role in a particular area and do not independently review what was proposed by management. Care must be taken when agreeing to undertake such a kind of work that does not compromise the independence of internal auditor.

Internal audit charter. Each unit of internal audit should have its charter that defines the organizational status of the Internal Audit Unit, purpose, mission, work objectives, accountability, and unit responsibility. The internal audit charter is suggested to include chapters as follows: Chapter-Contents-Mission-Purpose.

Responsibility - defines the reporting lines of the audit executives, the manner and form of reporting. The independence-determines the legal arrangements that ensure maintaining of independence. Authority-defines the internal audit rights to have access to records and communication with the organization's staff. The audit confirms that the practice standards will apply standards for internal audit.

Letter of management. An effective written report to the board of directors must contain an executive summary, which is an essential part of communication. The auditors will report the issues that have come to their attention during the course of the audit. These will include:

(1) Changes in the risk assessment that are an issue;

(2) Weaknesses in internal controls; 
(3) Weaknesses in management information systems;

(4) Comments on the work and support of internal audit;

(5) Issues related to the financial statements;

(6) Recommendations for change.

The management letters are private communications, which the board may delegate to the audit committee. They are considered by all relevant parties and are completely useful.

\section{The Relationship Between Internal and External Audit}

The coordination of internal audit activity with the external audit activity is very important from both points of view: From external audit's point of view, it is important because, in this way, external auditors have the possibility to raise the efficiency of financial statements audit; the relevancy from internal audit's point of view is assured by the fact that this coordination assures for the internal audit a plus of essential information in the assessment of risks control (L. Dobroteanu \& C. L. Dobroteanu, 2002).

The importance of the relationship from internal audit and external audit is reflected also by International Standards on Auditing (610 - "Considering the Work of Internal Audit"), which foresees, among others:

(1) The role of internal auditing is determined by management, and its objectives differ from those of the external auditor who is appointed to report independently on the financial statements. The internal audit function's objectives vary according to management's requirements;

(2) The external auditor should obtain a sufficient understanding of internal activities to identify and assess the risks of material misstatement of the financial statements and to design and perform further audit procedures;

(3) The external auditor should perform an assessment of the internal audit function, when internal auditing is relevant to the external auditor's risk assessments;

(4) The external auditor would ordinarily inform the internal auditor of any significant matters which may affect internal auditing.

The first relevant study regarding the interaction between internal audit and external audit was realized by Mautz (1984) and the results of this study showed that, from internal audit's point of view, the relationship with external audit is only ostensibly a very good one.

Later, Haron, Chambers, Ramsi, and Ismail's (2004) findings of the study indicated that technical competence and work performed are the two most important criteria that external auditors consider in their reliance on internal auditors.

\section{The Differences Between Internal and External Audit}

The main differences between internal and external audit can be summarized as follows:

The independence of internal auditors means independence within the organization but not the independence from the organization because the internal auditors are employees in the organization and therefore do not have the independence of external auditors. Despite this, the independence of internal audit is very important. They should be professional, impartial, and avoid any potential conflict.

In many companies, internal auditors are almost entirely dependent on executive managers of the company. In such cases, internal auditors are just business consultants of executive managers and the safety of objective that they offer to executive managers and board of directors is limited. For example: how can internal auditors 
report any potential deficiency to managers in the audit committee, when managers have the power of dismissal from work of internal auditors at any time?

Therefore, it is always much preferred for internal auditors to be more independent from managers, meaning that decisions about recruitment, dismissal from work, performance appraisal of internal auditors, etc. should be taken only by the audit committee of the board of directors which should be the only authority on internal auditors.

Being independent, internal auditors are cheaper in real reporting about the current situation in the organization including: financial situation, internal controls, risk management, leading business processes, etc. Consequently, executive managers and board of directors earn an objective security.

In organizations where the internal audit department is developing professional and usually has not conflict between this department and executive managers, internal auditors after every audit give their analysis with their recommendations. If executive managers fail to consider these recommendations and these are considered as important for the future of society by the internal auditors, then both sides need to defend their positions about the issue.

The recommendations of the internal auditors related to deficiencies, failures, and potential abuses in the organization, such as risk management, control, and leadership processes in society, give the internal auditors the title business consultants. The progressive departments of the managers offer various business consulting services to internal audit, so it is very important for internal auditors to be more qualified for the business aspect.

Internal auditors not only deal with the organization's financial controls, but also deal with all the internal controls of the organization. They constantly test and evaluate the effectiveness of controls designed to assist the company in achieving its objectives and goals. They help other members of the organization in performing their assignments and responsibilities are supplied with analysis, assessments, recommendations, and advices. For this reason, the internal auditors are considered as internal controls of the company, and even its auditing standards consider the internal audit as part of the monitoring component of internal control within the organization.

Auditing processes for both internal auditors and external auditors have changed in the past eight to ten years (Lemon \& Tatum, 2003). The main factors that prompted these changes included the globalization of business, advances in technology, and demands for value-added audits.

Figure 1 illustrates these changes in practice. 


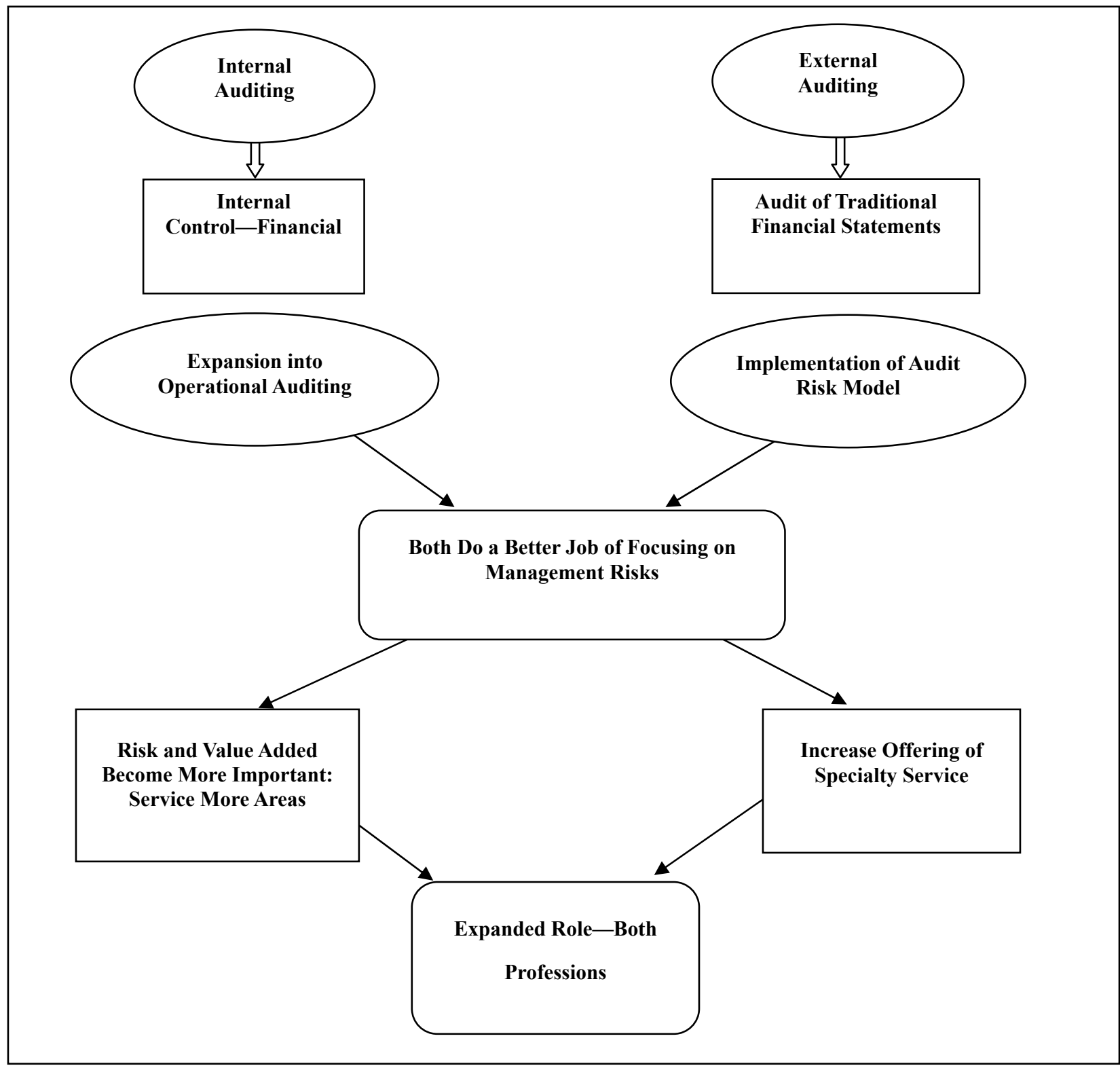

Figure 1. Convergence of internal audit and external audit functions. Source: Rittenberg \& Covaleski, 1997.

\section{Conclusions}

In this chapter are given the specific conclusions of the study, which are resulted from the analysis of the interviews.

(1) The duties and functions of each employee in the company are separated and defined by the position they have. In addition, there is cooperation between the personnel for solving various problems and fulfilling tasks;

(2) The nature of the company's audit, as internal and external includes financial control, fraud, financial resources, and the assessment of risk control of the company's activity;

(3) The audit practice had not set timeframe. Internal audit is carried out more often, while external audit is performed once a year; 
(4) The data analysis showed that the internal audit is more effective for managing the company;

(5) With regard to the necessary competencies and skills, it was concluded that the company does not have a separate section for audit;

(6) Data analysis showed that the internal audit is exercised rather than external audit inside the company;

(7) According to professionals, the audit often brings conflicts in the company due to the absence of a clear definition of audit instructions and lack of training on the importance or effectiveness of the audit;

(8) The staff did not perform an audit-specific training, because it is always carried out by the director of the company;

(9) Participants in the study admitted that in their work place, there is a lack of the instructions and the manuals for audit;

(10) Employees show that the audit helps them for a better performance and being more responsible in their work;

(11) One of the most important results of this study emphasizes that professional audit staff is important and must be given greater attention by the leaders. For this reason, it is recommended in the future to draft specific guidelines on auditing and implementation to be more frequent in order to achieve the effectiveness of management of the company. Also, it is recommended that more studies should be conducted on this topic for the future.

\section{References}

Dobroteanu, L., \& Dobroteanu, C. L. (2002). Audit: Concepts and practices: National and international access. Bucharest: International Publishing House.

Haron, H., Chambers, A., Ramsi, R., \& Ismail, I. (2004). The reliance of external auditors on internal auditors. Managerial Auditing, 19(9), 1148-1159.

Hay, D., Knechel, W. R., \& Willekens, M. (2014). The Routledge companion to auditing. Abingdon, Oxon: Routledge.

Holmes, A., \& Brown, S. (2000). Internal audit in higher education. London: Kogan Page.

Lemon, M. W., \& Tatum, K. W. (2003). Internal auditing's systematic, disciplined process, The Institute of Internal Auditors Research Foundation. Retrieved from https://na.theiia.org/iiarf/Public\%20Documents/Chapter\%208\%20Internal\%20Audit ings\%20Systematic\%20Disciplined\%20Process.pdf

Mautz, R. (1984). Internal and external auditors: How do they relate? Corporate Accounting, 3(4), 56-58.

Porter, B., Simon, J., \& Hatherly, D. (2011). Principles of external auditing (3rd ed.). Chichester, England; Hoboken, NJ: Wiley.

Rittenberg, L. E., \& Covaleski, M. (1997). The outsourcing dilemma: What's best for internal auditing. Altamonte Springs, Florida: The Institute of Internal Auditors Research Foundation.

Tourish, D., \& Hargie, O. (2009). Auditing organizational communication: A handbook of research, theory and practice (2nd ed.). East Sussex; New York, NY: Routledge.

Tricker, R. (2016). ISO 9001:2015 audit procedures (4th ed.). Oxford, United Kingdom: Oxford University Press. 